\title{
Microalgae is an unclaimed bioenergy resource in Russia
}

\author{
Yuri Kozhevnikov, Inna Knyazeva*, and Oksana Vershinina \\ FSBSI "Federal Scientific Agroengineering Center VIM", 109428, Russia
}

\begin{abstract}
There were considered the technological and biological aspects of the perspective of microalgae as a biological resource of alternative energy. An overview analysis of the current state of the art from the point of view of assessing the use of microalgae as a renewable raw material of high productivity for producing third-generation biofuels is presented. In recent decades, research in the field of technologies for the production of biomass of microalgae for energy purposes has focused mainly on the search for strains with a high oil content. In particular, it was found that the lipid content of some strains of algae can be increased to $65 \%$ by dry weight under conditions of reduced availability of nitrogen-containing nutrients. One of the directions in research is the use of a photobioreactor for accelerated cultivation of the microalgae Chlorella vulgaris Bin. Keywords: microalgae, bioenergy, biofuel.
\end{abstract}

\section{Introduction}

An important direction is the search for new methods of resource conservation, reduction of harmful effects on the environment and the creation of appropriate technologies and equipment that are in circulation in technical means of mechanization and operate on "traditional" types of fuel (gasoline, diesel fuel, fuel oil) [1,2].

Currently, about 1 billion tons of plant mass is used for the needs of the world energy sector, which is equivalent to $25 \%$ of world oil production. The potential of plant mass for energy use is 100 billion tons [3]. The production of biodiesel fuel from plant biomass is considered as one of the most promising alternative directions providing high indicators of stability and environmental efficiency in the transport area $[4,5]$.

Plant biomass can be considered as a natural biological converter and accumulator of solar energy in the form of chemical bonds. If necessary, the energy stored in this way can be used by direct combustion or conversion into other types of biofuels. The advantages of obtaining biodiesel from algae are a high growth rate and, therefore, a high yield per hectare of area. In addition, algae-derived biofuels are sulfur-free, non-toxic and highly biodegradable. In the conditions of a significant part of the territory of Russia, biomass is the most accessible local renewable fuel raw material, providing minimal transport costs and a relatively low cost of energy production [6].

\footnotetext{
* Corresponding author:knyazewa.inna@yandex.ru
} 
For years, research has been carried out on the use of algae biomass for the production of fuel, in particular microalgae. Most researchers associate the perspectives of using algae as a raw material for biofuel production with the presence of a significant proportion of the lipid fraction in some strains [7]. In addition, the unique properties of microalgae made it possible to classify the fuel produced from renewable biomass of microalgae as a "third generation" biofuel [8].

In recent decades, research in the field of technologies for the production of biomass of microalgae for energy purposes was carried out by a number of foreign companies and were mainly focused on the search for strains with a high oil content [9]. Encouraging results in this direction have been obtained in laboratory conditions using a number of biotechnological methods using genomic and biochemical technologies. Table 1 shows the lipid content in the biomass of microalgae of some strains considered as promising in terms of biodiesel production [10].

Table 1. Microalgae with high lipid content

\begin{tabular}{|c|c|c|}
\hline № & Microalgae species & Lipid content, \% (dry weight) \\
\hline 1 & Ankistrodesmusbraunii & 73 \\
\hline 2 & Chlorella protothecoides & 58 \\
\hline 3 & Neochlorisoleoabundans & 54 \\
\hline 4 & Pleurochrysiscarterae & 50 \\
\hline 5 & Nannochloropsis spp. & 41 \\
\hline 6 & Arthrospira (Spirulina) platensis & 29 \\
\hline 7 & Tetraselmissuecica & 25 \\
\hline 8 & Dunaliellatertiolecta & 23 \\
\hline 9 & Nannochlorisatomus & 21 \\
\hline 10 & Euglena gracilis & 20 \\
\hline
\end{tabular}

In particular, it was found that the lipid content of some strains of algae can be increased to $65 \%$ by dry weight under conditions of reduced availability of nitrogencontaining nutrients $[11,12]$.

With the existing variety of species and strains of microalgae, characterized by a very wide range of biochemical components, in real conditions, only a few strains can successfully adapt to the climatic and biotic conditions of open water bodies in most of Russia. Therefore, the cultivation of microalgae "exotic" strains with a high lipid content used as raw materials for the production of biodiesel should be based on photobioreactor technologies [13].

The aim of the study is the accelerated cultivation of the biomass of the microalgae Clorella vulgaris Bin. in a flow-through photobioreactor.

\section{Materials and methods}

On the basis of the Federal State Budgetary Scientific Institution «Federal Scientific Agroengineering Center VIM», Moscow, the photobioreactor was developed to study the processes of cultivation of microalgae. The photobioreactor is equipped with a pulsating hydrodynamic regime for feeding the nutrient solution, which provides an increase in the productivity of cultivation of microalgae up to $15 \%$ Fig. 1. 


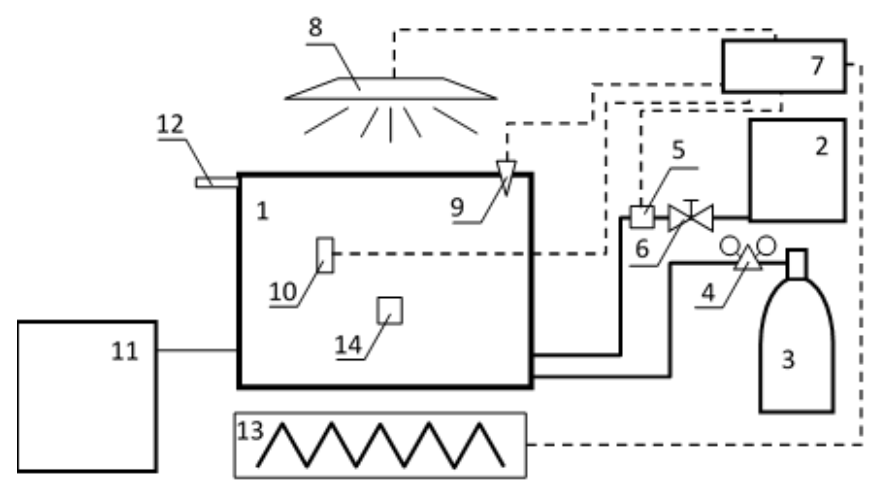

Fig. 1. Diagram of a photobioreactor with an intellectualized control system for the cultivation of microalgae : 1 - photobioreactor; 2 - raw material tank; 3 - $\mathrm{CO}_{2}$ cylinder; 4 - gas reducer; 5 - flow sensor; 6 - fine adjustment valve; 7 - control system of cultivation parameters; 8 - lighting system; 9 temperature sensor; 10 - microalgae concentration sensor; 11 - receiving container; 12 - branch pipe for the exit of excess gases (ventilation of the photobioreactor); 13 - thermostating system; 14 dissolved $\mathrm{CO}_{2}$ sensor

The microalgae strain Chlorella vulgaris Bin was used as the object of the research. To implement the cultivation process, the following conditions were maintained: temperature within $24-28{ }^{\circ} \mathrm{C}$, concentration of $\mathrm{CO}_{2}$ in a suspension of microalgae in water $400 \mathrm{mg} / \mathrm{L}$, illumination of a suspension of microalgae in water with light with wavelengths of red (660 $\mathrm{nm})$ and blue (445 $\mathrm{nm})$ spectra.

\section{Results and discussion}

One of the research directions is the use of a photobioreactor for accelerated cultivation of microalgae chlorella. A photobioreactor is a device designed to maintain vital activity and intensive reproduction of photosynthetic microorganisms. The reactor includes the following systems for supporting the vital activity of microalgae: a feeding system and removal of metabolites, a thermal stabilization system, a lighting system, a gas exchange system (Fig. 2).

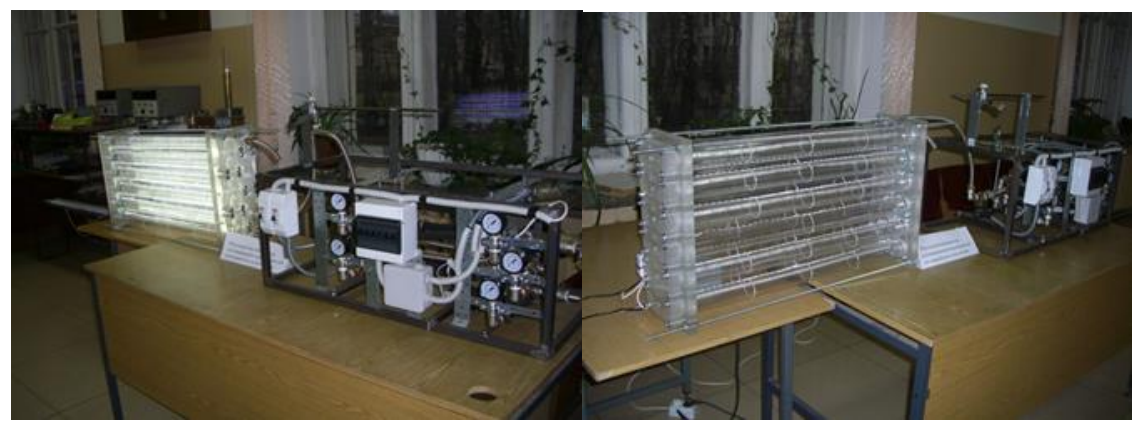

Fig. 2. Photobioreactor for research the processes of cultivation of microalgae FSA Center VIM

Experimental work to determine the nature of the growth rate of chlorella in different types of installations revealed that the optical density of the resulting biomass cultivated in a photobioreactor exceeds the control (cultivation in a bioreactor) by 11.8 ... 26.3\% (Fig. 3). 


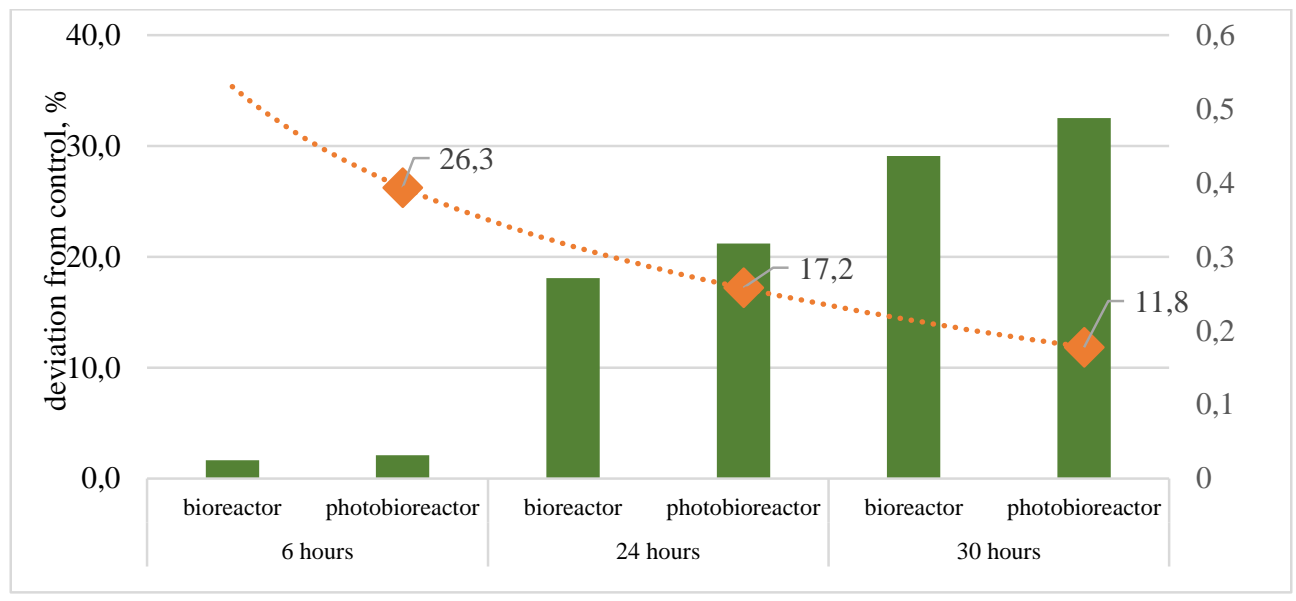

Fig. 3. Optical density of biomass of microalgae Clorellavul. Bin. with increasing experiment time

The difference in the optical density of the chlorella suspension is expressed in the tendency of a decrease in the deviation from the control biomass parameter with an increase in the experiment time. So, in the first 6 hours of cultivation, the difference was maximum $26.3 \%$, after 24 hours it decreased to $17.2 \%$ and after 30 hours of cultivation it was $11.8 \%$.

\section{Conclusions}

In temperate climate zones, where the cultivation of biomass of special strains of microalgae, characterized by a high fat content, is not economically justified, it is necessary to conduct research on the development of approaches and technologies for the use of microalgae in energy that are more acceptable under existing conditions. For a number of years, the Federal State Budgetary Scientific Institution VIM Center has been developing a concept and a technological base for the production of integrated use of microalgae biomass without its preliminary separation into fractions by preparing a boiler composite mineralorganic fuel. When carrying out experimental work on the cultivation of chlorella in a flowthrough photobioreactor, the dependence of a decrease in the growth rate of microalga biomass on an increase in the cultivation time was established. Throughout the entire period of chlorella cultivation, there was a tendency to an increase in the density of the suspension in relation to the control.

\section{References}

1. K.W. Chew, J.Y. Yap, P.L. Show, N.H. Suan, J.C. Juan,et.al. Bioresource Technology, 229 (2017)

2. Energy Strategy of Russia for the Period up to 2020. Decree of the Government of the Russian Federation No. 1234-r, 28.08.2003

3. J.G. Speight Chemistry. And Technology Of Alternate Fuels (2020)

4. T. Minowa, S.-ya Yokoyama, M. Kishimoto Okakura T., Fuel, 74, 12 (1995)

5. C.Rëatledge, Z., Lipid Technology, 20 (2008)

6. H.A. Aratboni, N. Rafiei, R. Garcia-Granados, A. Alemzadeh, J.R. Morones-Ramirez, Microb Cell Fact.,18 (2019)

7. D.L. Barreiro, C. Samorì, G. Terranella, U. Hornung, A. Kruse, W., Technol., 174 (2014) 
8. M.Vanthoor-Koopmans, R.H.Wijffels, M.J.Barbosa, M.H.M., Technol., 135 (2013)

9. K.Kumar, S.K.Mishra, A.Shrivastav, M.S. Park, J.-W. Yang, Renewable and Sustainable Energy Reviews, 51 (2015)

10. H.M.Amaroa, C.Guedes, X., Applied Energy, 88 (2011)

11. J.P. Fidalgo, A. Cid, E. Torres, A. Sukenik, C. Herrero, Aquaculture, 166, 1 (1998)

12. Y.Li, M.Horsman, B.Wang, N.Wu, C.Q. Lan , Applied Microbiology and Biotechnology, Springer Berlin, Heidelberg 81, 4 (2008)

13. Kirpenko N., Leontieva T., Biotechnologia Acta., 12, 6 (2019) 